\title{
Does Your Boss Know Where You Are? Predicting Adoption of LBS in the Workplace
}

\author{
Lisa Thomas $\quad$ Pam Briggs Linda Little
}

Pact Lab, Department of Psychology

Northumbria University

lisa.thomas@northumbria.ac.uk p.briggs@northumbria.ac.uk I.little@northumbria.ac.uk

\begin{abstract}
To date there has been no tested model to predict uptake of LBS services in a real world setting. The leading theoretical contribution to our understanding of attitudes and behaviour towards LBS comes from Junglas \& Spitzmüller (2005). They hypothesised that intentions to use LBS would be influenced by technology characteristics, task characteristics, personality type, perceived privacy, perceived usefulness, trust and perceived risk. We developed a questionnaire to test and refine their model with a UK employed population.
\end{abstract}

Location-Based Services (LBS), technology adoption, questionnaire development

\section{INTRODUCTION}

Location-Based Services (LBS) have been simply defined as 'services that take into account the geographic position of an entity' (Junglas, 2007). Such applications typically utilise GPS, Bluetooth, wireless networks and cell phone towers to pinpoint the location of a mobile phone (Porus \& Ellis, 2007).

Early applications had a strong focus on safety and security: for example in enhancing emergency service responses (Minch, 2004), or in aspects of child security - as with the 'Safe and Sound' system (Marmasse \& Schmandt, 2003), in which children were given mobile phones to carry, and both parents and children were notified with an alarm warning once the child strayed out of a predetermined area. Perhaps the ultimate security measure has been adopted in Australia, where police now have the power to fit people suspected of terrorist activities with tracking devices (Perusco \& Michael, 2007). Recent news reports suggest that law enforcement in the US has been exploiting an unknown location tracking capability of iPads and iPhones to aid in criminal investigations (McCullagh, 2011).

LBS has also had a social focus. In 2002, the US company AT\&T Wireless launched a 'Find Friends' service which allowed users to locate consenting friends and family members using a Global Positioning System (GPS) on their mobile phones (Lawson, 2002). Numerous social networking sites now offer people the chance to locate their friends using platforms such as Facebook Places and Foursquare.

Finally, LBS has had a workplace focus. Research has already shown that employees have different disclosure preferences for work colleagues (Olson, Grudin, \& Horvitz, 2005). In terms of LBS, one system developed to monitor employee interaction with colleagues suggested that even with privacy principles adhered to, acceptance of monitoring was limited (Zweig \& Webster, 2003). In a study of 387 employees in the US, UK and India, attitudes towards workplace monitoring were also found to be unfavourable (Workman, 2009). However, those who had greater perceptions of vulnerability, more self-efficacy and greater levels of trust 'were more amenable to monitoring' (p.229). It is clear that attitudes towards workplace monitoring are varied, and exploration of LBS in the workplace is lacking.

As the context for location-based services has grown, so has the need to develop a privacy model that establishes the impact of privacy on use and intention to use such services. We do know that there are clear differences in disclosure preferences when faced with revealing location information to friends, family, or colleagues (Consolvo, et al., 2005) and we also know some of the predictors of LBS use within a family setting (Thomas, Briggs, \& Little, 2010), but as yet, relatively little is known about LBS use within the 
workplace. In this paper, then, we build upon existing work in order to ask whether we can reasonably predict employee's intentions to use LBS.

Location-based services can be accessed in a variety of ways, however in this research the main focus has been LBS use within mobile phones. This research is in collaboration with North-East based company TrackaPhone, who provide various LBS tracking systems to customers. One example of their products is the Alert Client system (Figure 1). Alert Client enables panic buttons and escalation procedures to be used via the TrackaPhone platform.

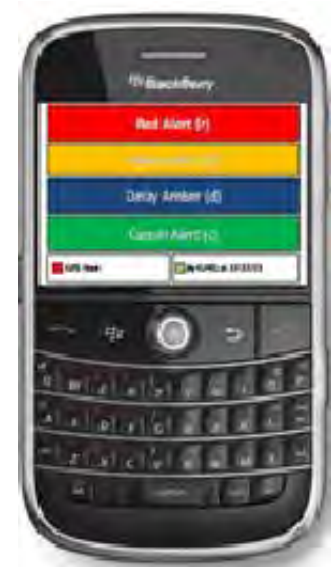

Figure 1: Alert Client view on the Blackberry ${ }^{\mathrm{TM}} 8800$

\section{DEVELOPING THE MODEL}

To date there has been no tested model to predict uptake of LBS services in a real world setting. The leading theoretical contribution to our understanding of attitudes and behaviour towards LBS comes from Junglas \& Spitzmüller (2005). They hypothesised that intentions to use LBS would be influenced by technology characteristics, task characteristics, personality type, perceived privacy, perceived usefulness, trust and perceived risk (Figure 2).

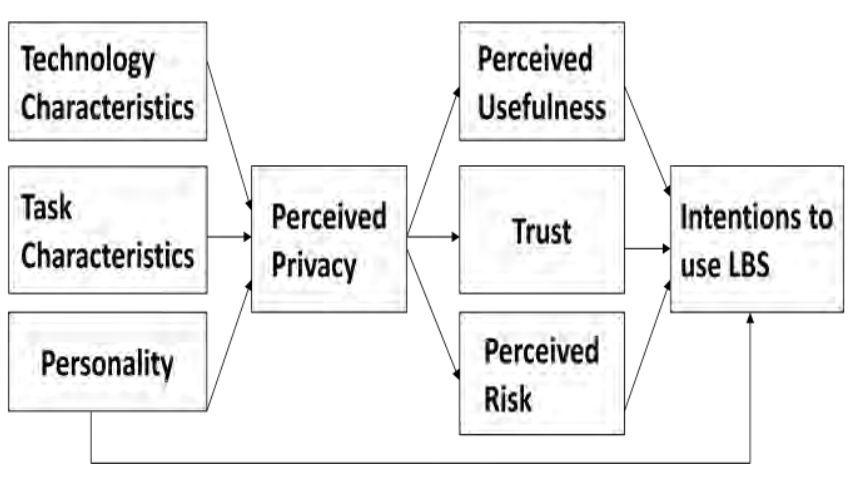

Figure 2: The Research Model (Junglas \& Spitzmüller, 2005)
We developed a questionnaire to refine and test the model. Questions for each component were either taken directly from suggestions made by Junglas \& Spitzmüller, or if no previously tested items existed, they were created independently during our research. The aim of this research is to test the suggested model using the specially designed questionnaire, which can then be refined and tested further. Each factor from the model will be briefly discussed.

\subsection{Task Characteristics}

Task characteristics may affect the way individuals perceive a tracking system. If employees are in an unfamiliar environment, for example, they may be more receptive to an LBS system than if they were at home. Questions relating to task characteristics included 'LBS would help if I was working in a dangerous area', or 'I would find location tracking acceptable if I was working in an unknown area'.

\subsection{Personality}

The Big Five personality traits (agreeableness, conscientiousness, emotional stability, extraversion and openness) have previously been tested as mediators of the intention to use LBS (Junglas, Johnson, \& Spitzmüller, 2008). It is hypothesized that more conscientious individuals will form intentions to use LBS, individuals scoring highly on neuroticism may be more likely to distrust LBS, and individuals more open to experiences are likely to have fewer LBS concerns (Junglas \& Spitzmüller, 2005). In accordance with the model, we measured conscientiousness and openness to experience (Gosling, Rentfrow, \& Swann, 2003), neuroticism (IPIP, 2009), and locus of control (Humphreys, 1993) with previously tested items.

\subsection{Perceived Privacy}

Four privacy items have been identified that relate to information exchange: collection of personal information, unauthorized secondary use of personal information, errors in personal information, and improper access to personal information (Smith, Milberg, \& Burke, 1996). Each factor is considered important to measure privacy concerns. The four privacy items were incorporated using previously defined questionnaire statements (Junglas, et al., 2008). The items were modified slightly to fit the LBS context, for example 'It bothers me if my employer stores my location information'.

In recent work, Concern for Information Privacy (CFIP) has been investigated using Structural Equation Modelling (Zhou, 2010), the hypothesis being that CFIP would positively affect perceived risk and negatively affect trust. Zhou also hypothesised that trust negatively affects risk and 
positively affects LBS usage intention. Results showed that concern about collection of information, errors in information, and unauthorised secondary use affected perceived risk and trust, which in turn determined usage of LBS.

\subsection{Perceived Usefulness}

Junglas (2007) hypothesised that perceptions of usefulness and ease of use would increase after initial usage of LBS. Participants showed that irrespective of the type of LBS task, they perceived a significant increase in usefulness. Items for perceived usefulness came from existing scales (Davis, Bagozzi, \& Warshaw, 1989), and were modified for our questionnaire so they related to LBS, for example 'Using LBS would improve my job performance'.

\subsection{Trust}

Research into trust items has divided the concept into three categories: Benevolence, Ability and Integrity (Mayer, Davis, \& Schoorman, 1995). Benevolence reflects the service provider's positive image as viewed from a consumer's perspective. Ability refers to perceived competence. Integrity refers to an organizations' adherence to rules. The trust items (Pavlou \& Gefen, 2004), were phrased in line with LBS, for example 'I feel that my employer is reliable'.

\subsection{Perceived Risk}

Risk has been proposed as 'inseparably intertwined' with trust issues, and is therefore hypothesized to be a direct antecedent of intentions to use LBS (Junglas \& Spitzmüller, 2005). For example, trust and perceived risk were found to be key mediators to predict intentions to use the online store Amazon (Pavlou, 2001). Perceived risk items came solely from Pavlou.

\subsection{Intentions to Use LBS}

Intention items were not prescribed by Junglas \& Spitzmüller, so other items from similar research were consulted (Vijayasarathy, 2004; Wang, Lin, \& Luarn, 2006). Items were created specifically for this questionnaire, such as 'I intend to use a device which would allow people to locate me during working hours'.

\section{METHOD}

Pilot study feedback suggested that wording of a number of statements were problematic for participants. These were amended, and the questionnaire was printed. This was then sent to 1,500 named individuals, using addresses from a market research company.

All participants were in some form of employment in the UK at the time of posting. Each questionnaire was sent out with a cover letter, consent form and pre-paid return envelope. We received 106 completed questionnaires back.

\section{RESULTS}

All data was entered into SPSS v.18 and screened for normality prior to analysis.

\subsection{Factor Analysis}

The analysis was run applying the principal-axis factoring method with Varimax rotation. Interpreting the output, 21 factors were identified. The questions relating to 'locus of control' were removed, as they did not fit well with the identified factors. Running a second factor analysis, 14 factors were identified. Looking at these results, it became clear that there were 11 main factors present in the data, so a further analysis with 11 factors as a cut-off was run. From this analysis, we identified the following 10 factors: Intentions to use LBS, Disclosure to employer, Neuroticism, Employer responsibility, Perceived Usefulness, Out of work tracking, Trust of the employer, Trust of the LBS provider, Perceived Risk, and Conscientiousness.

\subsection{Regression}

We then conducted a step-wise logistical regression to understand which of the 10 factors would predict intentions to use LBS. We wanted to understand which of the factors would predict intentions to use LBS in the workplace, so removed the 'out of work tracking factor'. This regression would then tell us what predicted LBS use within working hours. Model 3 shows that three factors emerged as predicting intentions to use LBS: perceived usefulness $\left(R^{2}=.207\right)$, trust of LBS provider $\left(R^{2}=.280\right)$, and disclosure to employer $\left(R^{2}=.331\right)$. Coefficients can be seen in Table 1 . 
Table 1: Coefficients following stepwise multiple regression

\begin{tabular}{clll}
\hline & B & SE B & $\beta$ \\
\hline Model 1 Constant & .440 & .502 & \\
Perceived usefulness & .502 & .098 & $.455^{* *}$ \\
Model 2 & & & \\
Constant & -.512 & .566 & \\
Perceived usefulness & .450 & .095 & $.408^{* *}$ \\
Trust of LBS provider & .362 & .113 & $.275^{*}$ \\
Model 3 & & & \\
$\quad$ Constant & .873 & .747 & \\
Perceived usefulness & .397 & .094 & $.360^{* *}$ \\
Trust of LBS provider & .340 & .110 & $.258^{*}$ \\
Disclosure to employer & -.236 & .086 & $-.231^{*}$ \\
\hline
\end{tabular}

${ }^{* *} p<.001,{ }^{*} p<.05$

$R^{2}=.207$ for Model $1(p<.001), \Delta R^{2}=.073$ for Model 2

$(p<.05), \Delta R^{2}=.050$ for Model $3(p<.05)$.

\subsection{Structural Equation Modelling}

From the regression analysis, we then tested this revised model using Structural Equation Modelling. The factors of Perceived Usefulness, Trust of LBS provider, and Disclosure to employer were drawn as predictors of Intention to Use LBS (Figure 3). The model was drawn in Amos Graphics v.18, and the data from the questionnaire was applied.

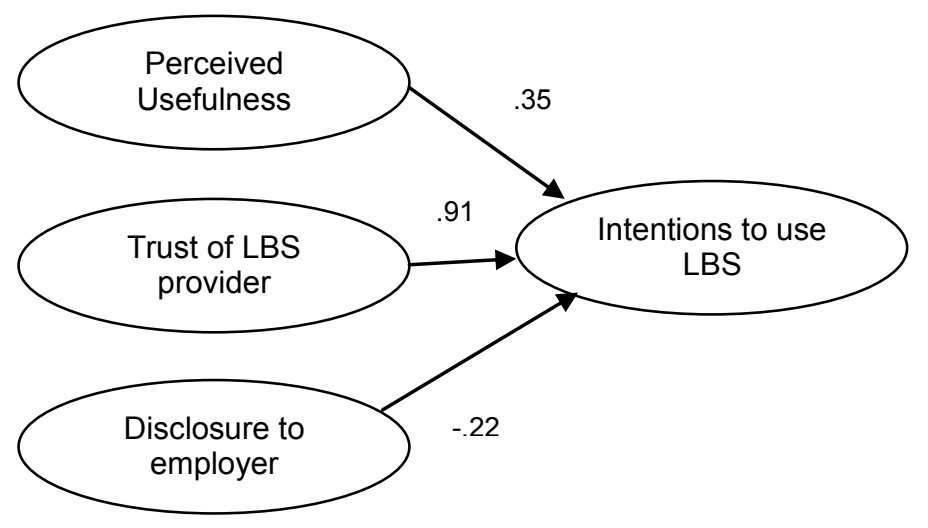

Figure 3. SEM analysis including three factors from regression

The model suggested by principal components analysis yielded fit indices of .85 (CFI and IFI), indicating a fairly good fit. However, the $X^{2}$ value for the model, with 133 degrees of freedom, was 344.3 $(p=.000)$, and the RMSEA was .123 , suggesting a poor fit. These contradictory SEM findings suggest that our model could be improved, but also that the use of SEM may not be appropriate for this particular phase of our research. It has been highlighted that SEM analysis assumes the sample size is large, but in psychology in general, numbers may not reach more than a few hundred (Werner \& Schermelleh-Engel, 2009; Westland, 2010).

\section{FUTURE WORK}

Taking this into consideration, we plan to refer to the regression output to determine any other factors which correlate highly with intentions to use LBS. For example, when we ran a regression with all items entered as independent variables, 'trust of employer' also emerged as being a factor in the model. The factors identified as predictive of LBS adoption will be included in a revised questionnaire. The issue of sample size will be rectified using a much larger scale (1000+ participants) for the second questionnaire, sent online to employees in the UK and US.

\section{RESEARCH CONTRIBUTION}

Despite this research only being part one of a two phased investigation the analysis already suggests that the model suggested by Junglas \& Spitzmüller (2005) does not predict intentions to use LBS in a work context. We aimed to create a questionnaire to fit the model exactly, yet when looking at factor analysis and regression results, concepts such as personality type do not seem to be important when thinking about LBS adoption. This phase of the research suggests that perceived usefulness of the LBS system, trust of service providers, and the expectations of the employer determine if employees would be willing to use LBS.

\section{REFERENCES}

Consolvo, S., Smith, I., Matthews, T., LaMarca, A., Tabert, J., \& Powledge, P. (2005). Location Disclosure to Social Relations: Why, When, and What People Want to Share. Paper presented at the Proceedings of the SIGCHI conference on Human Factors in Computing Systems.

Davis, F., Bagozzi, R., \& Warshaw, P. (1989). User Acceptance of Computer Technology: A Comparison of Two Theoretical Models. Management Science, 35(8), 982-1003.

Gosling, S., Rentfrow, P., \& Swann, W. (2003). A Very Brief Measure of The Big-Five Personality Domains. [Article]. Journal of Research in Personality, 37(6), 504-528.

Humphreys, P. (1993). BPS Manual of Psychology Practicals: Experiment, Observation and Correlation: Wiley-Blackwell. 
IPIP (2009). (International Personality Item Pool). A Scientific Collaboratory for the Development of Advanced Measures of Personality Traits and Other Individual Differences. Retrieved 16.06.2009: http://ipip.ori.org/newNEODomainsKey.htm

Junglas, I. (2007). On The Usefulness And Ease of Use of Location-Based Services: Insights Into The Information System Innovator's Dilemma. International Journal of Mobile Communications, 5(4), 389-408.

Junglas, I., Johnson, N., \& Spitzmüller, C. (2008). Personality Traits and Concern for Privacy: an Empirical Study in the Context of Location-Based Services. [Article]. European Journal of Information Systems, 17(4), 387-402.

Junglas, I., \& Spitzmüller, C. (2005). A Research Model For Studying Privacy Concerns Pertaining To Location-Based Services. Paper presented at the Proceedings of the Annual Hawaii International Conference on System Sciences, United States.

Lawson, S. (2002). AT\&T Wireless Helps Callers Find Friends. Retrieved 13 November 2008, from http://www.pcworld.com/article/102269/atandt wirel ess helps callers find friends.html

Marmasse, N., \& Schmandt, C. (2003). Safe \& Sound: a Wireless Leash. Paper presented at the $\mathrm{CHI}$ '03 extended abstracts on Human factors in Computing Systems.

Mayer, R., Davis, J., \& Schoorman, F. (1995). An Integrative Model of Organizational Trust. Academy of Management Review, 20(3), 709-734.

McCullagh, D. (2011). How police have obtained iPhone, iPad tracking logs. CNET News: Privacy INC Retrieved 28.4.11, from http://news.cnet.com/8301-31921 3-20056344281.html

Minch, R. (2004). Privacy Issues in Location-Aware Mobile Devices, Piscataway, United States.

Olson, J., Grudin, J., \& Horvitz, E. (2005). A Study of Preferences for Sharing and Privacy. Paper presented at the $\mathrm{CHI}$ '05 extended abstracts on Human factors in Computing Systems.

Pavlou, P. (2001). Integrating Trust in Electronic Commerce with the Technology Acceptance Model: Model Development and Validation. AMCIS 2001 Proceedings.(Paper 159).

Pavlou, P., \& Gefen, D. (2004). Building Effective Online Marketplaces with Institution-Based Trust. Information Systems Research, 15(1), 37-59.
Perusco, L., \& Michael, K. (2007). Control, Trust, Privacy, and Security: Evaluating Location-Based Services. [Article]. IEEE Technology and Society Magazine, 26(1), 4-16.

Porus, J., \& Ellis, M. (2007). Location-Based Services And Presence Technology: The Future of Telecommunications Is Closer Than You Think. Harris Interactive, The Harris Report. Retrieved 23 January 2009, from http://www.harrisinteractive.com/news/newsletters/ HarrisReport/HI TheHarrisReport 2007 v02 i01.p df

Smith, J., Milberg, S., \& Burke, S. (1996). Information Privacy: Measuring Individuals' Concerns About Organizational Practices. MIS Quarterly, 20(2), 167-196.

Thomas, L., Briggs, P., \& Little, L. (2010). The impact of using location-based services with a behaviour-disordered child: a case study. Paper presented at the Proceedings of the 6th Nordic Conference on Human-Computer Interaction: Extending Boundaries.

Vijayasarathy, L. R. (2004). Predicting consumer intentions to use on-line shopping: the case for an augmented technology acceptance model. Information \& Management, 41(6), 747-762.

Wang, Y., Lin, H., \& Luarn, P. (2006). Predicting Consumer Intention to Use Mobile Service. Information Systems Journal, 16(2), 157-179.

Werner, C., \& Schermelleh-Engel, K. (2009). Structural Equation Modeling: Advantages, Challenges, and Problems: Goethe University, Frankfurt.

Westland, C. J. (2010). Lower bounds on sample size in structural equation modeling. Electronic Commerce Research and Applications, 9(6), 476487.

Workman, M. (2009). A field study of corporate employee monitoring: Attitudes, absenteeism, and the moderating influences of procedural justice perceptions. Inf. Organ., 19(4), 218-232.

Zhou, T. (2010). The Impact of Privacy Concern on User Adoption of Location-Based Services. from Hangzhou Dianzi University: www.emeraldinsight.com/journals.htm?articleid=19 $\underline{01920 \& \text { show }=p d f}$

Zweig, D., \& Webster, J. (2003). Personality as a Moderator of Monitoring Acceptance. Computers in Human Behavior, 19(4), 479-493. 